\title{
Tellurite-based fibers and their applications to optical communication networks
}

\author{
Atsushi MORI ${ }^{\dagger}$ \\ NTT Photonics Laboratories, NTT Corporation, 3-1, Morinosato-Wakamiya, Atsugi-shi, Kanagawa 243-0198
}

This paper reviews tellurite-based fibers and their applications to optical communication networks. First, an investigation of tellurite-based glass and the fabrication of conventional step-index fibers and photonic crystal fibers (PCF) are described. By purifying the raw materials and employing a novel PCF fabrication process, low background losses were achieved for an $\mathrm{Er}^{3+}$ doped, an undoped tellurite-based fiber and a tellurite-based PCF. Second, the optical properties of Er ${ }^{3+}$-doped tellurite-based glass and fiber, and the gain characteristics of erbium doped tellurite fiber amplifiers (EDTFAs) were studied. A seamless, low noise and gain flattened $C+L$ band EDTFA was realized, and an $S+C+L$ band amplifier was constructed by combining an EDTFA and a thulium-doped fluoride fiber amplifier (TDFFA) in parallel. Third, it is confirmed that the Raman scattering characteristic of tellurite-based fiber has such a large gain coefficient and Stokes shift that it is possible achieve a wideband tellurite-based fiber Raman amplifier. To overcome several problems, a distributed/discrete hybrid tellurite- and silica-based fiber Raman amplifier (FRA) was constructed as an S + C + L band WDM repeater with a gain bandwidth of 127-nm. Fourth, Brillouin amplification and the simulated performance of slow light generation in a tellurite-based fiber were investigated. The fiber exhibits the largest time delay per unit power of $19.9 \mathrm{~ns} / \mathrm{mW}$. Finally, a carrier-envelope offset (CEO)-locked frequency comb with low fiber coupling pulse energy $(230 \mathrm{pJ})$ was demonstrated by using a tellurite-based PCF. This method has the potential to lock the CEO with a lower pulse energy and thus provide a low-noise and high-accuracy optical frequency comb at telecommunication wavelengths. These tellurite-based fibers with low background loss thus offer attractive functions for applications in the optical communication field.

(02008 The Ceramic Society of Japan. All rights reserved.

Key-words : Optical fiber materials, $\mathrm{Er}^{3+}$-doped fiber amplifier, Fiber Raman amplifier, Brillouin scattering, Slow light generation, Carrier-envelope offset locking, Frequency comb

[Received June 30, 2008]

\section{Introduction}

The tremendous success of the deployment of silica-based fiber and waveguides in the photonic network has motivated an investigation of highly functional photonic devices for more flexible and robust transmission systems. Silica is advantageous as an optical medium because of its good transparency and high reliability, but its functionality, which is based on refractive index change and the stimulated emission of doped rare earth, is limited. The small number of raw materials that can be used for conventional fabrication processes such as vapor-phase axial deposition (VAD) or modified chemical vapor deposition (MOCVD) leads to less material diversity. A large number of fiber materials have been proposed with a view to realizing novel functionalities that are unobtainable with conventional high-silica optical fiber. Phosphate, fluorophosphate, fluoride, bismuth, tellurite, and chalcogenide glasses have been reported as host materials for rare earth doped fiber amplifiers. ${ }^{1)-7)}$ Bismuth, tellurite and chalcogenide glasses have been reported for use in fabricating highly nonlinear fibers. ${ }^{8)-10)}$ The former requires a high doping concentration and a wide operating wavelength range for $\mathrm{Er}^{3+}$ ions or low phonon energy for $\mathrm{Pr}^{3+}$ and $\mathrm{Tm}^{3+}$ ions as glass characteristics. The latter also needs high linear and nonlinear refractive indices. The advantage of tellurite-based fiber for photonic device applications originates not only in these two characteristics, but also in its low fiber attenuation.

Corresponding author: A. Mori; E-mail: a-mori@aecl.ntt.co.jp
Since the mid 1990s, the growth in Internet use and increases in data traffic in optical fiber communication networks have triggered the demand for increased wavelength-division multiplexing (WDM) transmission capacity. However, the available channels in WDM transmission systems are limited by the gain bandwidth of optical amplifiers. Wide-band optical fiber amplifiers have therefore been recognized as indispensable devices for future optical networks. In 1997, an $\mathrm{Er}^{3+}$-doped tellurite-based fiber amplifier (EDTFA) was proposed for amplification in the $\mathrm{C}$ (1530-1565 nm)-band and L (1565-1625 nm)-band gain bandwidths without a parallel configuration. ${ }^{11)}$ The key characteristics of $\mathrm{Er}^{3+}$-doped tellurite-based glass lie in its large stimulated emission cross-section at around $1600 \mathrm{~nm}$, and the shift in the ESA spectrum to a longer wavelength that results from the crystalline field effect on $\mathrm{Er}^{3+}$ ions induced by the surrounding tellurite-based ions. ${ }^{12)}$

With a view to practical EDTFA use, a great effort has been made to reduce tellurite-based fiber attenuation by purifying the raw materials. ${ }^{13)}$ A low loss of $20 \mathrm{~dB} / \mathrm{km}$ was finally achieved and this reduction opens up the possibility for many nonlinear applications including Raman amplifiers, Brillouin amplifiers and slow light. ${ }^{9), 14)}$ Silica-based fibers have been widely employed in these applications as a matter of course. However, to obtain an effective gain or time delay requires a fiber length of several or several tens of kilometers because of the low Raman and Brillouin gain coefficients of silica-based fiber. This would increase the size of the fiber module packages and the cost of the devices. We need to reduce the fiber length for practical use, and 
fiber with a high nonlinear refractive index has good potential for such applications. An important advantage of tellurite-based fiber is that its background loss is less than one-tenth those of bismuth-oxide based fiber ${ }^{15)}$ and $\mathrm{As}_{2} \mathrm{Se}_{3}$ chalcogenide fiber. ${ }^{16)}$ This lower background loss means a larger effective length defined as $L_{\text {eff }}=(1-\exp (-\alpha L)) / \alpha$ and also a larger gain $G=10 \log \left[\exp \left(g_{\mathrm{R}, \mathrm{B}} L_{\mathrm{eff}} P K / A_{\mathrm{eff}}-\alpha L\right)\right],{ }^{17)}$ which is an important parameter for amplifiers, and slow light generation (where, $\alpha, \mathrm{L}$, $g_{\mathrm{R}, \mathrm{B}}, P, K$ and $A_{\text {eff }}$ are the absorption coefficient, the fiber length, the Raman and the Brillouin gain coefficients, the pump power, the polarization factor ${ }^{18)}$ and the effective mode area, respectively).

When applying tellurite-based fiber to nonlinear devices that employ a parametric process in a telecommunication window, the zero-dispersion wavelength of the fiber should be controlled near the $1.5-\mu \mathrm{m}$ band. ${ }^{19)}$ However, the tellurite-based fiber employed for Raman amplification has a large chromatic dispersion of around $-166 \mathrm{ps} / \mathrm{nm} / \mathrm{km}$ at $1550 \mathrm{~nm}$, which causes no signal degradation as a result of four-wave mixing owing to the phase mismatch of the signals. ${ }^{20)}$

With photonic crystal fiber (PCF) we can realize fiber with a high nonlinear coefficient $\gamma$. However, PCFs with a small-core large-NA structure cause significant anomalous waveguide dispersion, and so a zero-dispersion wavelength in the $1.5-\mu \mathrm{m}$ band has not been obtained using silica-based PCFs with a high $\gamma$ of more than $100 \mathrm{~W}^{-1} \mathrm{~km}^{-1}$ due to their intrinsic material dispersion properties. ${ }^{21)}$ In contrast, most nonlinear compound glasses with a large material nonlinearity $\left(n_{2}\right)$ exhibit a highly normal dispersion of around $-100 \mathrm{ps} / \mathrm{nm} / \mathrm{km}$ at $1550 \mathrm{~nm}$, which means it is possible to achieve a zero-dispersion wavelength near $1550 \mathrm{~nm}$. By employing the significant anomalous waveguide dispersion obtained with a glass and air hole structure, it was possible to fabricate a tellurite-based PCF with a zero-dispersion wavelength of around $1.55 \mu \mathrm{m}^{22)}$ The PCF also exhibited a high $\gamma$ of 675 $\mathrm{W}^{-1} \mathrm{~km}^{-1}$ and a minimum loss of $180 \mathrm{~dB} / \mathrm{km}$. This PCF with a high $\gamma$ and a large $L_{\text {eff }}$ offers the possibility of realizing high performance functional devices operating in the $1.5-\mu \mathrm{m}$ band. The PCF was employed to generate an octave bandwidth supercontinuum (SC) and a carrier-envelope offset (CEO)-locked frequency comb including a telecommunication window. ${ }^{23)}$ The inventors of the CEO-locked frequency comb technique, which controls optical field waveforms directly through precise control of the carrier-envelope phase, were awarded a Nobel prize in 2005, and the comb is employed as an optical frequency ruler in the hundreds of terahertz range. ${ }^{24)-26)}$

This paper reviews research on tellurite-based glasses and fibers, and their applications. This paper is organized as follows. Section 2 describes research on tellurite-based glass and the fabrication of conventional step-index fibers and PCF. Section 3 describes the optical properties of $\mathrm{Er}^{3+}$-doped tellurite-based glass and fiber, and the gain characteristics of EDTFAs. Section 4 presents the stimulated Raman scattering and Raman gain characteristics of tellurite-based fibers. Section 5 investigates the Brillouin gain performance and the potential performance with a view to using tellurite-based fiber for slow light generation. Section 6 demonstrates octave bandwidth SC generation and its application to a CEO-locked frequency comb using telluritebased PCF. The paper concludes with a summary of these results.

\section{Tellurite-based glasses and fiber fabrication}

\subsection{Tellurite-based glasses}

Tellurite-based glasses are composed of $60-90 \mathrm{~mol} \% \mathrm{TeO}_{2}$ and many kinds of secondary components such as alkali earths and alkali oxides. The glasses exhibit the following characteristics. (i) They have a sufficiently wide transmission region $(0.35-$ $5 \mu \mathrm{m}$ ) for the $1.5-\mu \mathrm{m}$ telecommunication window, (ii) they have good thermal stability $\left(T_{x}-T_{\mathrm{g}}>100^{\circ} \mathrm{C}\right)$ and corrosion resistance $\left(10^{-5}-10^{-6} \mathrm{~g} \cdot \mathrm{cm}^{-2} \cdot \mathrm{d}^{-1}\right)$, (iii) they have a relatively low phonon energy among oxide glass formers $\left(h \omega=650-800 \mathrm{~cm}^{-1}\right)$, and (iv) they have a high refractive index and a high nonlinear refractive index $\left(n_{\mathrm{D}}=1.8-2.3, n_{2}=10^{-19}-10^{-18} \mathrm{~m}^{2} / \mathrm{W}\right)$. Wang et al have made a detailed comparison of the properties of tellurite, silica, fluoride and chalcogenide glasses. ${ }^{27)}$ They investigated the binary systems $\mathrm{TeO}_{2}-\mathrm{BaO}, \mathrm{TeO}_{2}-\mathrm{ZnO}$ and $\mathrm{TeO}_{2}-\mathrm{WO}_{3}$, which have a wide glass forming region, and added alkali oxides to them to obtain a UV edge, durability in $\mathrm{H}_{2} \mathrm{O}$ and rare earth solubility. As the result, they achieved a wide compositional range with the $\mathrm{TeO}_{2}-\mathrm{ZnO}-\mathrm{R}_{2} \mathrm{O}$ system, where $\mathrm{R}$ is $\mathrm{Li}, \mathrm{Na}, \mathrm{K}, \mathrm{Rb}, \mathrm{Cs}$ or Ag, to satisfy the three specific needs. Furthermore, the $\mathrm{TeO}_{2}-$ $\mathrm{ZnO}-\mathrm{R}_{2} \mathrm{O}$ system was investigated for low-loss fiber fabrication and the $\mathrm{TeO}_{2}-\mathrm{Bi}_{2} \mathrm{O}_{3}-\mathrm{ZnO}-\mathrm{Li}_{2} \mathrm{O}$ (TBZL) or $\mathrm{Na}_{2} \mathrm{O}$ (TBZN) system was found to have greatly improved thermal stability. This led to the fabrication of tellurite-based fibers whose core and cladding glass compositions are controlled to change the $\mathrm{Bi}_{2} \mathrm{O}_{3}$ content for the TBZL or TBZN system.

\subsection{Step-index tellurite-based fibers}

Tellurite-based fiber was fabricated using the elongation and jacketing-drawing method shown in Fig. 1. The preforms and jacketing tube were prepared by suction-casting and rotational casting methods, respectively. ${ }^{28), 29)}$ All the operations in the melting and casting processes used for fabricating the preform and jacketing tube were carried out in a clean dry gas atmosphere. High-purity $\mathrm{TeO}_{2}$ was prepared as a raw starting material from Te metal whose purity exceeded $6 \mathrm{~N} .{ }^{13)}$ Almost all the commercially obtained $\mathrm{TeO}_{2}$ raw material contained more or less yellow or gray $\mathrm{TeO}_{3}$, or black $\mathrm{TeO}$. By controlling the drying condition when forming $\mathrm{TeO}_{2}$ by wet-chemical synthesis so that its valency did not change, high purity $\mathrm{TeO}_{2}$ raw material was realized that was pure white. The other raw materials were commercially available and more than $99.9 \%$ pure. All the raw materials were weighed and mixed, and melted in gold crucibles at $800^{\circ} \mathrm{C}$. The preform was first elongated together with a cylindrical jacketing tube into a composite perform to reduce the core diameter. The composite preform was drawn into a fiber with a taper jacketing tube to obtain a fixed core diameter and a UV-curable acrylate coating.

Figure 2 compares the transmission losses of tellurite-based EDFs fabricated using commercial $\mathrm{TeO}_{2}$ raw material (fiber 1) and the developed high-purity $\mathrm{TeO}_{2}$ (fiber 2). Optical absorptions of around 800, 980 and $1400 \mathrm{~nm}$ correspond to the ${ }^{4} \mathrm{I}_{9 / 2}-{ }^{4} \mathrm{I}_{15 / 2}$, ${ }^{4} I_{11 / 2}-{ }^{4} I_{15 / 2}$ and ${ }^{4} I_{13 / 2}-{ }^{4} I_{15 / 2}$ ground state absorption in $\mathrm{Er}^{3+}$. The background loss of fiber 1 was $900 \mathrm{~dB} / \mathrm{km}$ at $1230 \mathrm{~nm}$. By contrast, fiber 2 exhibited a low background loss of $27 \mathrm{~dB} / \mathrm{km}$ at 1230 $\mathrm{nm}$. This result indicates that the background loss of telluritebased fibers strongly depends on the purity of the $\mathrm{TeO}_{2}$ raw material.

Figure 3 compares the loss spectra of tellurite-based fiber modules without $\mathrm{Er}^{3+}$ ion doping fabricated using the same raw materials as those used for fiber 2 in Fig. 2 (module 1) and raw materials dehydrated by using vacuum degassing (module 2 ). The modules are composed of 250-m long tellurite-based fibers and two V-groove connection parts with high NA silica fibers. The loss increases beyond $1400 \mathrm{~nm}$ and around $1550 \mathrm{~nm}$ of module 1 are caused by fundamental and overtone $\mathrm{OH}$ ion absorption, respectively. Conversely, module 2 exhibited consid- 

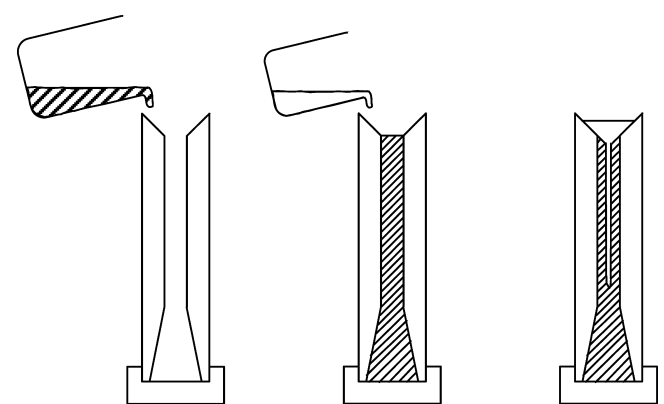

(a) Suction casting method

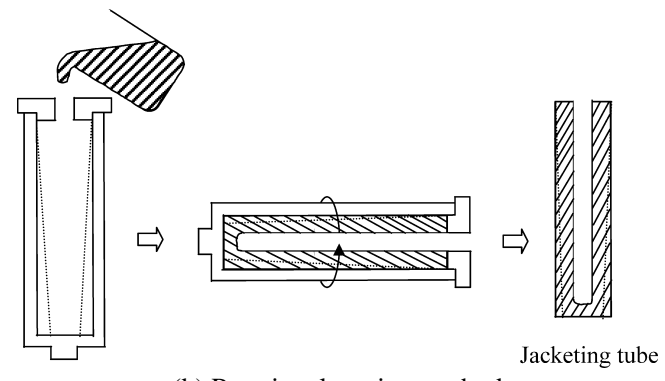

(b) Rotational casting method

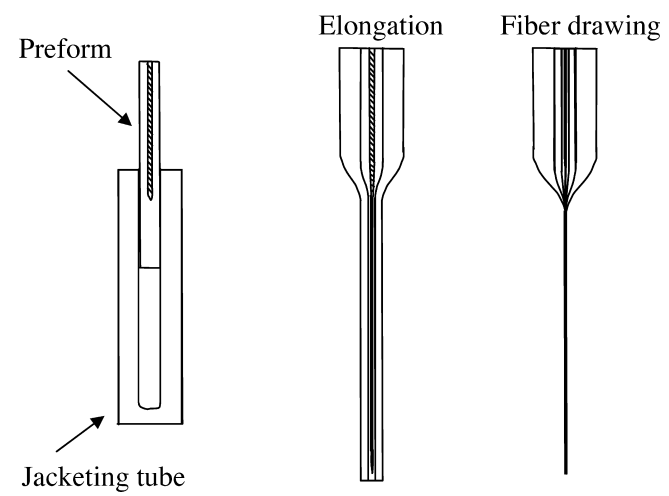

(c) Fiber fabrication process

Fig. 1. Tellurite-based fiber fabrication process (a) suction casting method, (b) rotational casting method, (c) fiber fabrication process.

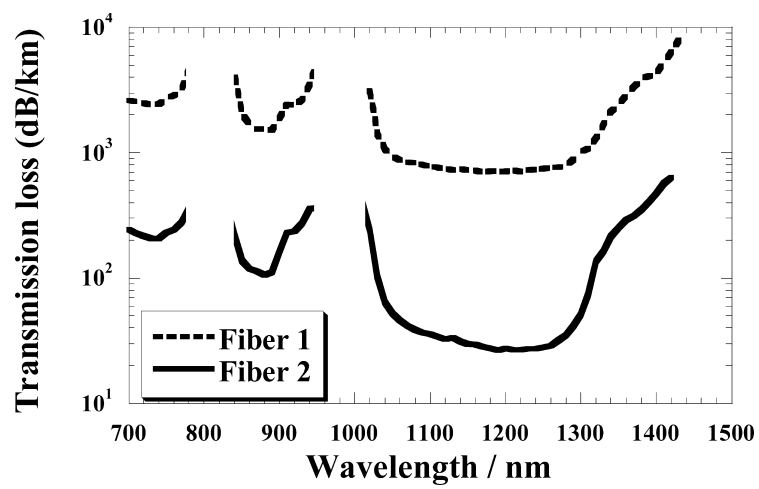

Fig. 2. Transmission losses of tellurite-based EDFs fabricated using commercial $\mathrm{TeO}_{2}$ raw material (fiber 1) and the high-purity $\mathrm{TeO}_{2}$ we developed (fiber 2).

erably less $\mathrm{OH}$ ion absorption and achieved a low background loss of $20 \mathrm{~dB} / \mathrm{km}$ at $1560 \mathrm{~nm}$. Since nonlinear applications such as Raman fiber amplifiers require tellurite-based fiber with a length of 200-300 m, the Raman gain characteristics depend

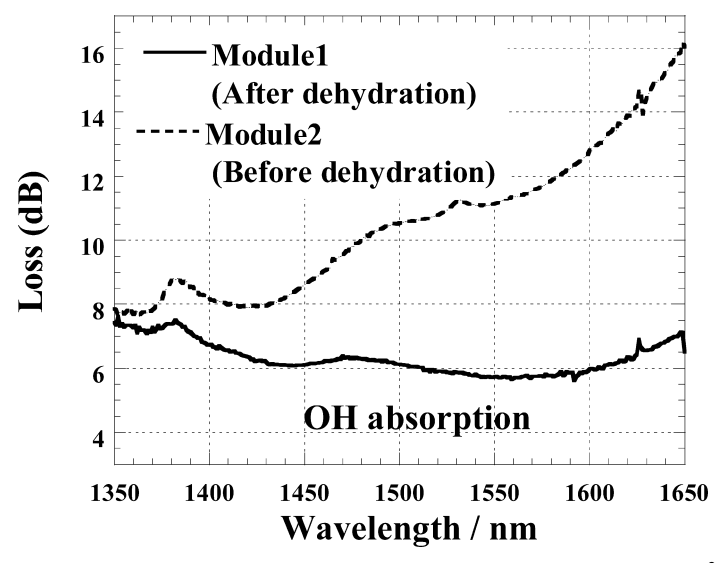

Fig. 3. Loss spectra of tellurite-based fiber modules without $\mathrm{Er}^{3+}$ ion doping fabricated using same raw materials as those used for fiber 2 (module 1) and dehydrated raw materials (module 2).

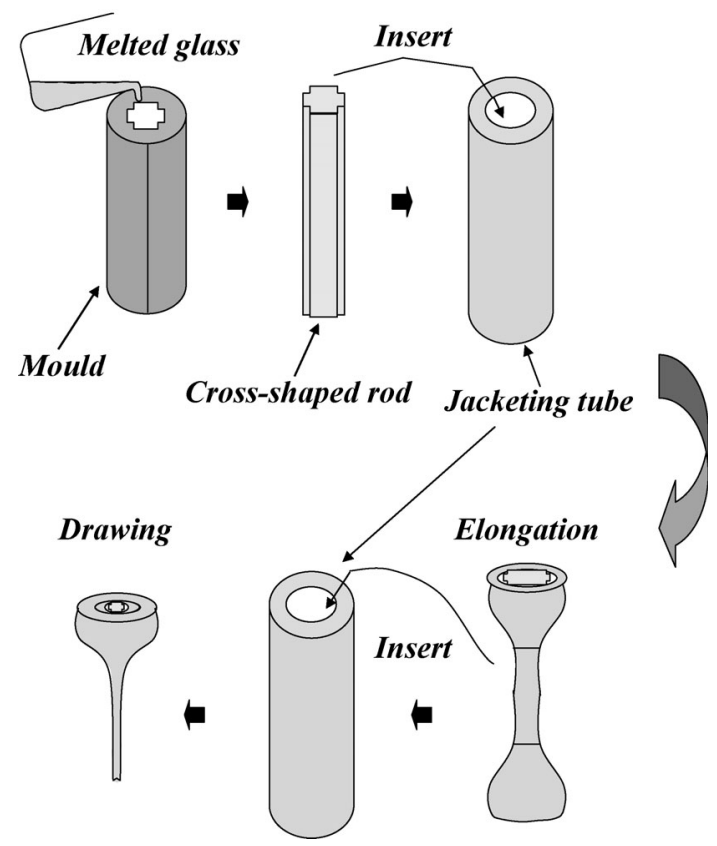

Fig. 4. Tellurite-based PCF fabrication process.

directly on this loss reduction in the $1.5 \mu \mathrm{m}$ wavelength region. ${ }^{9)}$

\subsection{Tellurite-based photonic crystal fiber ${ }^{22)}$}

The $\mathrm{TeO}_{2}$-based glass used to fabricate the PCF exhibits a high linear coefficient of 2.04 at $1550 \mathrm{~nm}$ and a nonlinear refractive index of $5.9 \times 10^{-19} \mathrm{~m}^{2} / \mathrm{W}$. To realize the glass and air hole structure of the PCF the new fabrication method shown in Fig. 4 was developed. With this process, a cross-shaped glass rod is prepared by casting melted glass into a cross-shaped mold. The fiber fabrication process is the same as that mentioned in 2.2. The fabricated tellurite PCF was more than $1.2 \mathrm{~km}$ long with core sizes in the $2.6-2.9 \mu \mathrm{m}$ range.

In order to design a core glass and cladding air hole structure so that the PCF has a zero-dispersion wavelength around 1550 $\mathrm{nm}$, a semi-vectorial mode calculation was performed using the finite difference method to determine the optical properties of the structure. Figure 5 shows zero-dispersion wavelength as function of core size and the defined structure model (inset). The core 
size for the zero-dispersion wavelength at $1550 \mathrm{~nm}$ was predicted to be $2.45 \mu \mathrm{m}$. Figure 6 shows SEM images of the PCF. The core size, outer hole diameter and outer fiber diameter were 2.6, 25 and $110 \mu \mathrm{m}$, respectively. The predicted effective mode area $A_{\text {eff }}$ for a core size of $2.6 \mu \mathrm{m}$ was $3.54 \mu \mathrm{m}^{2}$. Therefore the $\gamma$ value is calculated to be $675 \mathrm{~W}^{-1} \mathrm{~km}^{-1}$.

Figure 7 shows the propagation loss spectrum of the PCF. The minimum loss of the PCF was $180 \mathrm{~dB} / \mathrm{m}$ at $1400 \mathrm{~nm}$. The loss increases beyond $1400 \mathrm{~nm}$ and around $1550 \mathrm{~nm}$ are caused by fundamental and overtone $\mathrm{OH}$ ion absorption, respectively. Therefore, the loss increases to $400 \mathrm{~dB} / \mathrm{km}$ around $1550 \mathrm{~nm}$. It is speculated that the difference between the losses of the PCF and the tellurite-based fiber for a FRA is attributable to surface roughness and $\mathrm{OH}$ ions on the fiber surface. Therefore the appli-

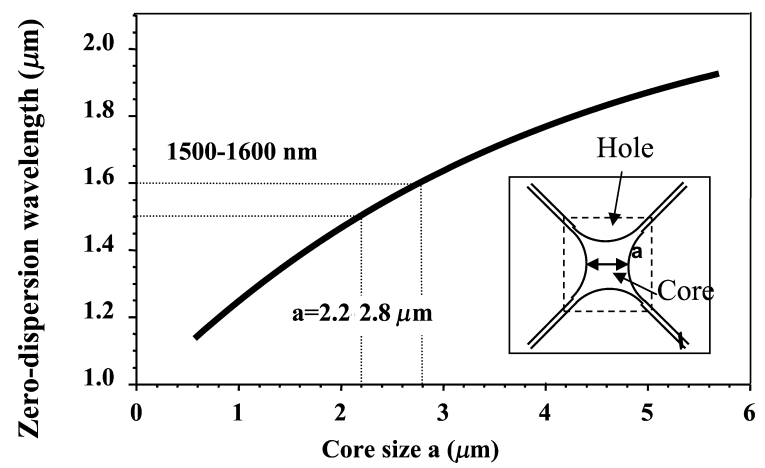

Fig. 5. Calculated zero-dispersion wavelength as a function of core size a and the defined model structure (inset). cation of a polishing and etching process to the glass rod surface is expected to result in an improvement in the optical loss. ${ }^{30)}$ The minimum loss was less than one tenth the value obtained for compound glass-based PCFs. ${ }^{31-33)}$

The material dispersion of the tellurite glass was derived by second order differentiating the measurement curve of the refractive index dispersion with respect to wavelength. This material dispersion is shown in Fig. 8. The dispersion at $1550 \mathrm{~nm}$ was around $-100 \mathrm{ps} / \mathrm{nm} / \mathrm{km}$ and the zero-dispersion wavelength was $2290 \mathrm{~nm}$. Figure 8 also shows the chromatic dispersion curve of the tellurite PCF with a core size of $2.6 \mu \mathrm{m}$. The dispersion curve was measured using a Fourier-transformed cross correlation. ${ }^{34)}$ The zero-dispersion wavelength was successfully shifted towards the $1.5-\mu \mathrm{m}$ band. The exact zero-dispersion wavelength was $1573 \mathrm{~nm}$, which agrees well with the simulated wavelength of $1575 \mathrm{~nm}$ for a core size of $2.6 \mu \mathrm{m}$.

\section{3. $\mathrm{Er}^{3+}$-doped tellurite-based fiber amplifiers}

Since EDFAs operate as three-level laser systems, the gain coefficient, $G$, can be written as $G \propto \sigma_{\mathrm{e}}(\lambda) N_{2}-\sigma_{\mathrm{a}}(\lambda) N_{1}$, and therefore depends on the population inversion rate. Here $N_{1}$ and $N_{2}$ are the population densities of the upper and lower energy levels, respectively. $\sigma_{\mathrm{e}}(\lambda)$ and $\sigma_{\mathrm{a}}(\lambda)$ are the stimulated emission and absorption cross-sections for wavelength $\lambda$, respectively. The population inversion rate can be controlled by controlling the pump power or EDF length used for EDFAs. By contrast, the stimulated emission and the absorption cross-sections depend on the Stark splitting of $\mathrm{Er}^{3+}$ ions induced by the crystalline field of the host.
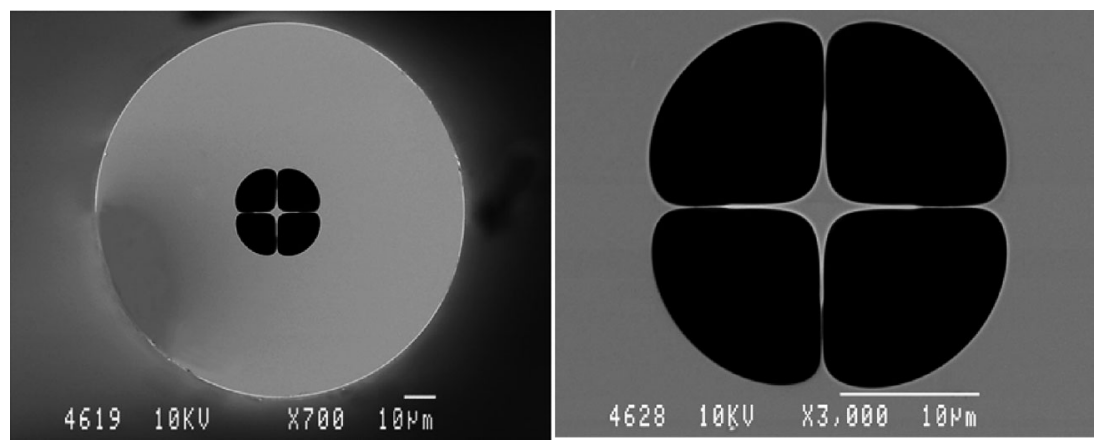

Fig. 6. SEM images of PCF.

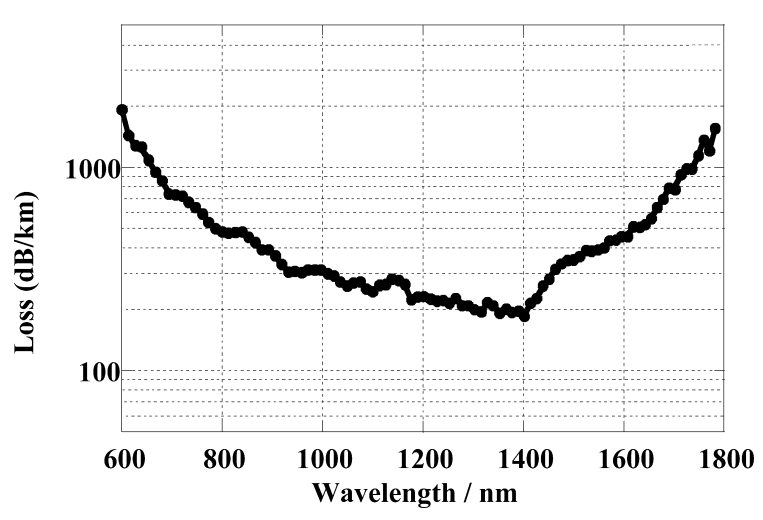

Fig. 7. Propagation loss spectrum of PCF.

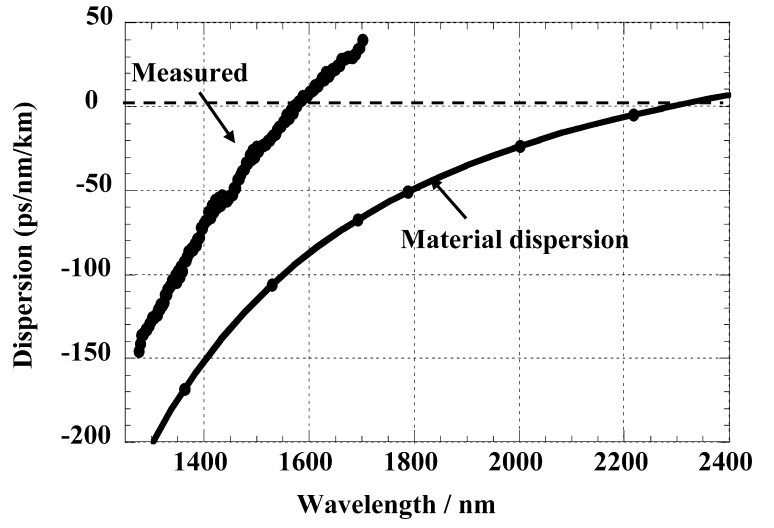

Fig. 8. Chromatic dispersion curve of tellurite PCF and tellurite glass material. 


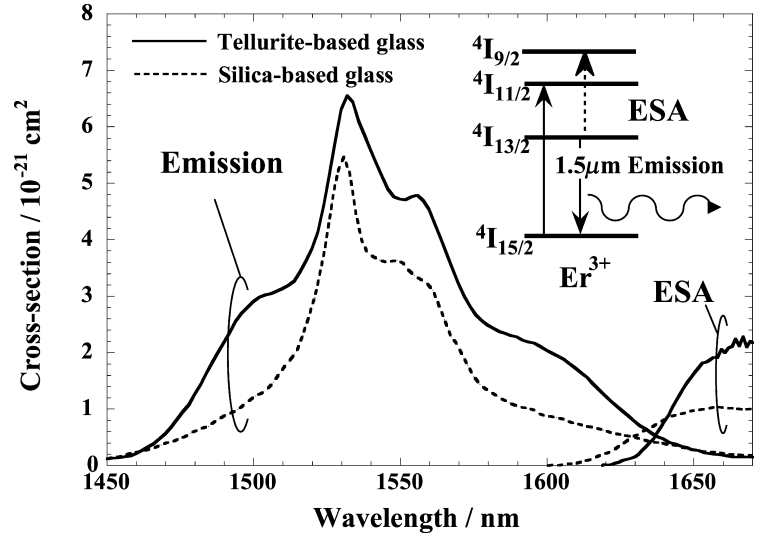

Fig. 9. ${ }^{4} \mathbf{I}_{13 / 2}-{ }^{4} \mathrm{I}_{15 / 2}$ stimulated emission and ${ }^{4} \mathrm{I}_{13 / 2}-{ }^{4} \mathrm{I}_{9 / 2}$ excited state absorption (ESA) cross-sections of $\mathrm{Er}^{3+}$ in tellurite and silica-based glasses.

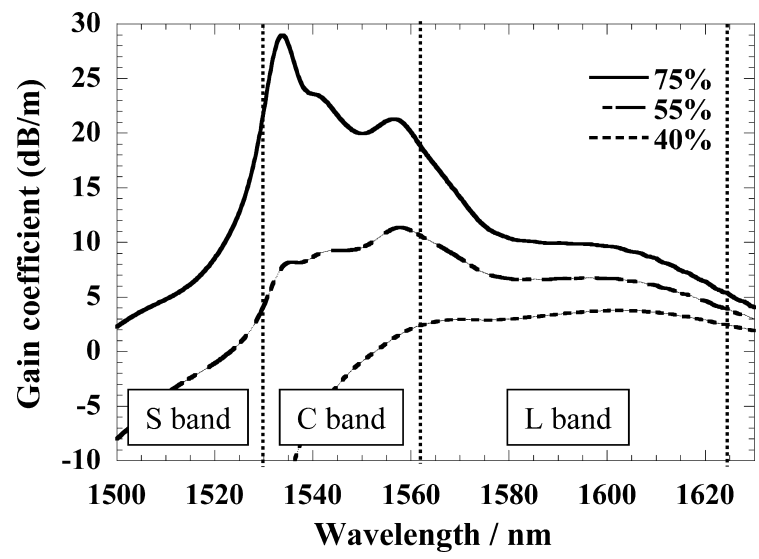

Fig. 10. Calculated spectra of different population inversion rates for EDTFAs.

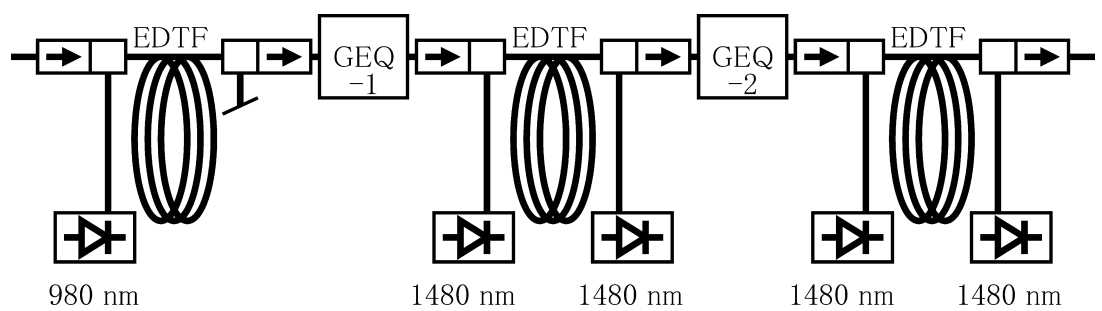

Fig. 11. Diagram of three-stage $\mathrm{C}+\mathrm{L}$ band EDTFA.

Figure 9 shows the ${ }^{4} I_{13 / 2}{ }^{4} I_{15 / 2}$ stimulated emission and ${ }^{4} I_{13 / 2}-$ ${ }^{4} \mathrm{I}_{9 / 2}$ ESA cross-sections of $\mathrm{Er}^{3+}$ in tellurite and silica-based glasses. The stimulated emission spectrum of Er ions in telluritebased glass is larger than that in silica-based glass over the entire 1450-1600 nm wavelength range and, in particular, the crosssection at around $1600 \mathrm{~nm}$ is double that in silica-based glass. Furthermore, the longer operation wavelength limit, which is defined as the point at which the ESA and the stimulated emission cross-section are equal, is shifted to a longer wavelength. These two advantages lead to a wider amplification band and a longer wavelength region.

Figure 10 shows calculated spectra of different population inversion rates for EDTFA. The inversion rates are $75 \%, 55 \%$ and $40 \%$, which give us gain-flattened $\mathrm{C}, \mathrm{C}+\mathrm{L}$ and L-bands, respectively. EDTFAs are advantageous in the 55\% and $40 \%$ operation bands, which include the L-band wavelength region. When controlling the inversion rate with a 55\%, EDTFA a $\mathrm{C}$ and L-band operation bandwidth of around $80 \mathrm{~nm}$ was achieved in the $1530-1610 \mathrm{~nm}$ region. With regard to $\mathrm{C}$ and L-band operation, an EDTFA is superior to an EDSFA in terms of gain excursion. However, even an EDTFA needs a gain equalization of 20$30 \mathrm{~dB}$ to achieve a flattened gain beyond $20 \mathrm{~dB}$ in the $\mathrm{C}$ and $\mathrm{L}$ band wavelength range. Therefore, to realize both a low noise figure and a high output power, the EDTFA employs a threestage configuration and uses $980-\mathrm{nm}$ band pumping for the first stage amplifier. ${ }^{35)}$ Figure 11 is a diagram of the EDTFA. The second and third stages were bidirectionally pumped with 1480$\mathrm{nm}$ LDs. Gain equalizers (GEQs) were inserted between the first and second stages, and between the second and third stages to achieve a flattened gain and large output power simultaneously. Figure 12 shows the gain and noise figure spectra for various input signal powers. A 70.8-nm gain bandwidth (from 1532.7 to

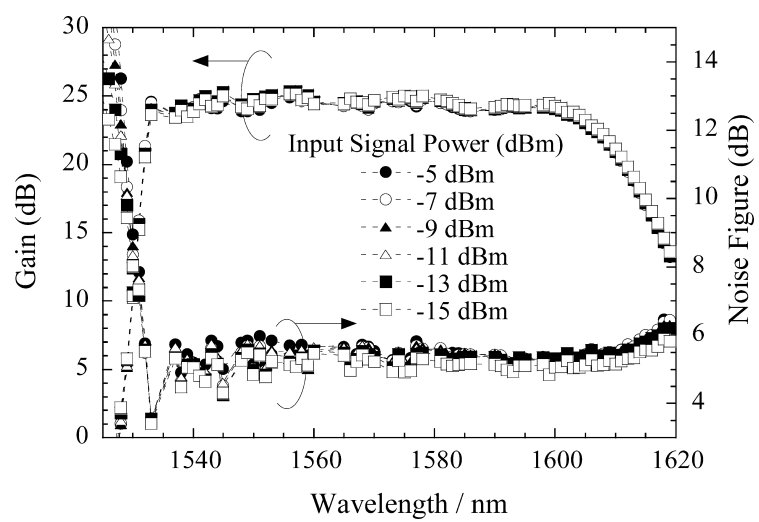

Fig. 12. Gain and noise figure spectra of EDTFA for various input signal powers.

$1603.5 \mathrm{~nm}$ ) was obtained, with a gain excursion of less than 1.5 $\mathrm{dB}$, an average gain of $24.3 \mathrm{~dB}$ and a noise figure of less than 6 $\mathrm{dB}$ for input signal powers of -15 to $-5 \mathrm{dBm}$.

Furthermore, when a long EDF is employed and the inversion rate controlled at a low value of $40 \%$, the EDTFA exhibits wide L-band operation. The L-band EDTFA is advantageous in the extended L-band wavelength region beyond $1610 \mathrm{~nm}$ where an EDSFA cannot obtain sufficient gain. Practical gain flattened Lband and extended L-band EDTFAs have been developed. ${ }^{36), 37)}$

By combining an EDTFA and a thulium doped fluoride fiber amplifier (TDFFA) in parallel, a coarse WDM amplifier was constructed for 8-channel WDM signals with 20-nm wavelength intervals thus allowing the effective use of the low loss wavelength range of installed transmission fibers around $200 \mathrm{~nm}$ with 
a loss of less than $0.25 \mathrm{~dB} / \mathrm{km}$. This amplifier achieved a total gain bandwidth of $148 \mathrm{~nm}$ with an average gain of $22.5 \mathrm{~dB}$, a noise figure of less than $8 \mathrm{~dB}$ and a gain excursion of $2 \mathrm{~dB} .^{38)}$ The amplifier can be used to upgrade a dense WDM amplifier with a high output power by employing higher pump powers for future ultra-high capacity WDM transmissions.

\section{Tellurite-based fiber Raman amplifiers}

With an FRA, a pump light of frequency $v$ is scattered by optical phonons (vibrational mode) with a frequency $\nu_{R}$ of the molecules that compose the core glasses and is consequently emitted with a frequency of $v-v_{\mathrm{R}}$. By making use of this energyconversion phenomenon, the signals can be amplified with a wavelength that is longer than that of the pump light simply with the molecular vibration frequency $v_{\mathrm{R}}$. Furthermore, a multiwavelength pumping technique has been used in FRAs to achieve wideband amplification as shown in Fig. 13. With this technique, the optical fiber used for Raman amplification is pumped with multi-wavelength light and a wide amplification band is achieved by overlaying the Raman gain spectra thus obtained.

The Raman gain spectrum of silica-based fiber consists of Si$\mathrm{O}$ and $\mathrm{Ge}-\mathrm{O}$ vibrations of $440 \mathrm{~cm}^{-1}$. Because the gain coefficient for $\mathrm{Ge}-\mathrm{O}$ is eight times larger than that for $\mathrm{Si}-\mathrm{O}$, a core glass with large amounts of $\mathrm{GeO}_{2}$ is advantageous for achieving a large gain coefficient. ${ }^{39)}$ The Raman gain spectrum for telluritebased fiber is the result of the 665 and $440 \mathrm{~cm}^{-1}$ stretching vibrations of $\mathrm{TeO}_{4}$ trigonal bipyramids, and of the $740 \mathrm{~cm}^{-1}$ stretching vibration of $\mathrm{TeO}_{3}$ trigonal pyramids. ${ }^{40)}$ When $\mathrm{TeO}_{2}$ is predominant in the glass composition it exhibits $\mathrm{TeO}_{4}$ trigonal bipyramids. As the network modifier grows, the structure changes into $\mathrm{TeO}_{3}$ trigonal pyramids. Furthermore, by modifying the glass components or adding components such as $\mathrm{P}_{2} \mathrm{O}_{5}$, and $\mathrm{WO}_{3}$ to tellurite-based glasses, the Raman spectra could be modified to some extent. ${ }^{41)}$

Figure 14 compares the gain coefficient spectra of telluritebased and silica-based fiber, and Table 1 summarizes their stimulated Raman scattering characteristics. Tellurite-based fiber with a refractive index difference $(\Delta n)$ of $2.2 \%$ and a scattering loss of $20 \mathrm{~dB} / \mathrm{km}$ at $1.56 \mu \mathrm{m}$, and a silica-based fiber (commercially available dispersion-compensation fiber) with a scattering loss of $0.6 \mathrm{~dB} / \mathrm{km}$ at $1.56 \mu \mathrm{m}$ were used. To measure the Raman gain spectra, each fiber was pumped with $1460-\mathrm{nm}$ LDs in a backward pumping scheme. It is clear that the maximum gain coefficient for the tellurite-based fiber was $55 \mathrm{~W}^{-1} \mathrm{~km}^{-1}$, which was 16 times larger than the value of $3.5 \mathrm{~W}^{-1} \mathrm{~km}^{-1}$ for the silicabased fiber. The Stokes shift of the main gain peak for the telluritebased fiber was $170 \mathrm{~nm}$, which was 1.7 times larger than that for the silica-based fiber. The most significant difference between these spectra was their spectral shape. The tellurite-based fiber had a twin-peaked spectrum, while the silica-based fiber had a spectrum with a single peak. These features make it possible to extend the seamless amplification bandwidth to $170 \mathrm{~nm}$ by using a short length of tellurite-based fiber as the amplification medium, whereas the amplification bandwidth is limited in principle to $100 \mathrm{~nm}$ when using a long silica-based fiber.

The tellurite-based FRA can provide a gain bandwidth of 170 $\mathrm{nm}$ and cover the low loss region of transmission fiber across the $\mathrm{S}$ (1460-1530 nm), C and L bands. However, when a telluritebased FRA is used as an inline repeater in an actual WDM system, the following problems must be dealt with: (1) a flat gain of over $20 \mathrm{~dB},(2)$ dispersion compensation, (3) noise figure degradation in the $S$ band, and (4) the signal power transfer from the

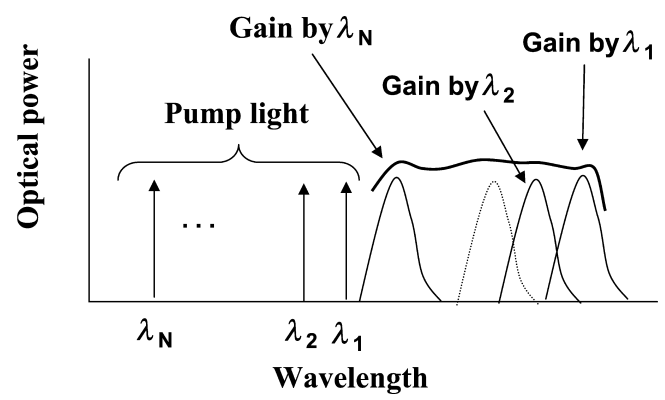

Fig. 13. Multi-wavelength pumping technique for wideband Raman amplification.
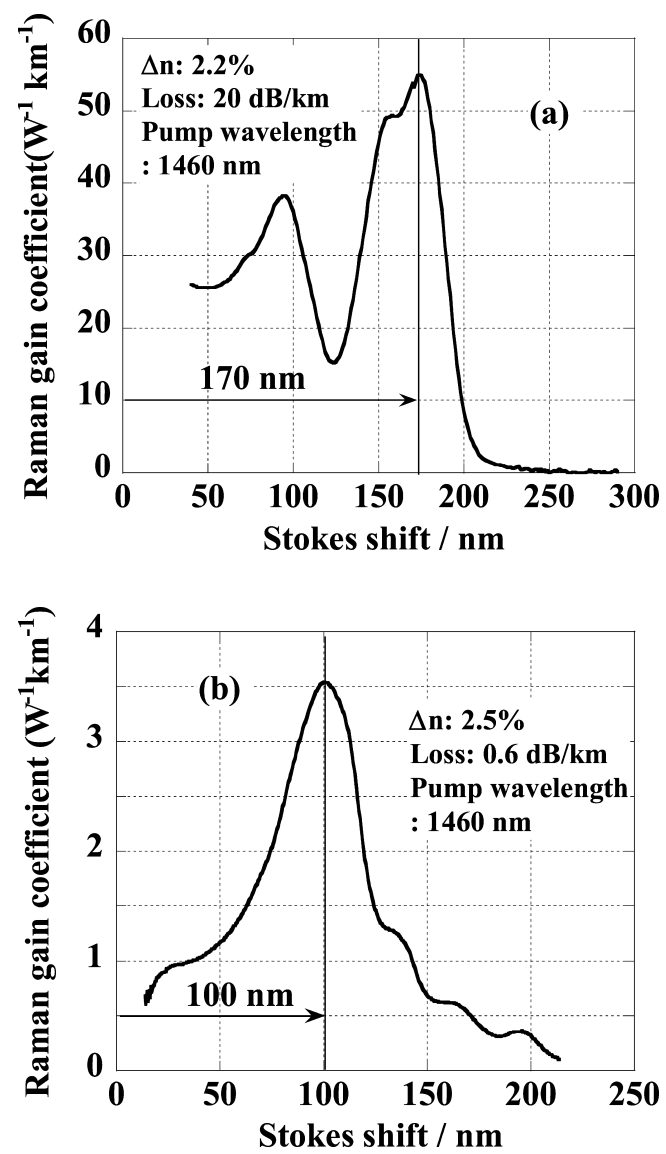

Fig. 14. Raman gain coefficient spectra (a) tellurite-based fiber, (b) silica-based fiber.

Table 1. Stimulated Raman Scattering Characteristics of Tellurite- and Silica-based Fiber

\begin{tabular}{lccc}
\hline & Max.gain coefficient & Stokes shift & Remarks \\
\hline Tellurite & $55 \mathrm{~W}^{-1} \mathrm{~km}^{-1}$ & $\sim 170 \mathrm{~nm}$ & Twin peaks \\
Silica & $3.5 \mathrm{~W}^{-1} \mathrm{~km}^{-1}$ & $\sim 100 \mathrm{~nm}$ & Single peak \\
\hline
\end{tabular}

S to L band caused by stimulated Raman scattering between optical signals in transmission fiber. As regards the first two problems, the differences between the gain spectra of telluriteand silica-based FRAs were examined and a discrete hybrid tellurite and silica FRA were configured that can achieve both dispersion compensation and gain flattening for linear repeaters. 


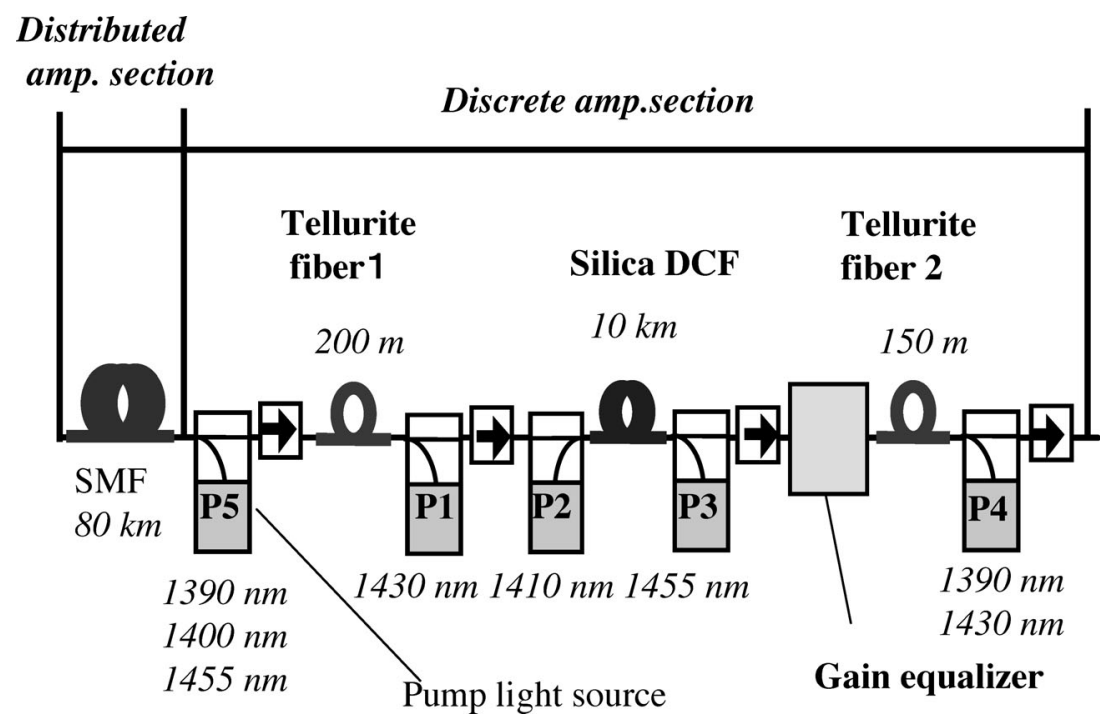

Fig. 15. Configuration of hybrid tellurite/silica FRA with distributed silica Raman amplification.

For the other two problems, a distributed/discrete hybrid FRA was configured that adds a distributed FRA with a high signal to noise ratio (SNR) centered on the $\mathrm{S}$ band to the discrete hybrid FRA. Here, the distributed FRA allows the transmission fiber itself to be used as the amplification medium, whereas the discrete FRA needs the amplifier fiber as the amplification medium.

Figure 15 shows the amplifier configuration. ${ }^{42)}$ This optical amplifier has a two-stage configuration with the distributed FRA section as the first stage and the discrete FRA section as the second stage. The discrete FRA section itself consists of three stages connected in series with tellurite-based fiber for the first and third stages and silica DCF for the second stage. A GEQ was placed between the second and third stages. The distributed FRA section consists of $80 \mathrm{~km}$ of single-mode fiber as transmission fiber, which is backward pumped by LDs operating at three wavelengths. The pump wavelengths and powers were determined in order to give this amplifier a low noise figure and high output as well as a flat gain spectrum. Figure $\mathbf{1 6}$ shows the total gain spectrum with and without gain equalization, and the equivalent noise figure. The equivalent noise figure is computed as the net noise figure (defined as the loss between the input end of the 80-km single-mode fiber (SMF) and the amplifier output) minus the SMF loss in $\mathrm{dB}$ units. The figure also shows the loss spectra for $80 \mathrm{~km}$ of SMF. The total gain spectrum after equalization indicates an average gain of $22 \mathrm{~dB}$ across the $127-\mathrm{nm}$ wavelength region of 1480-1607 nm. For an 80-km SMF loss of 15.5-18 dB, a system margin of about $3 \mathrm{~dB}$ can be obtained in the same band. For the same wavelength regions, the equivalent noise figure is less than $7 \mathrm{~dB}$. The low equivalent noise figure in the short wavelength region was specifically designed to suppress the SNR degradation caused by the stimulated Raman scattering that occurs between optical signals in this region in high-speed large-capacity transmission systems. This amplifier was used as a linear repeater in a large-capacity WDM experiment of 313 channels with a channel rate of $10 \mathrm{Gbit} / \mathrm{s}$. The results showed that this amplifier could achieve error-free operation seamlessly across a 124-nm (1485-1609 nm) gain band. This is the widest seamless amplification band yet reported. ${ }^{43)}$

Some calculations have been performed to obtain a wideband and flat gain spectrum with only tellurite-based FRA operated

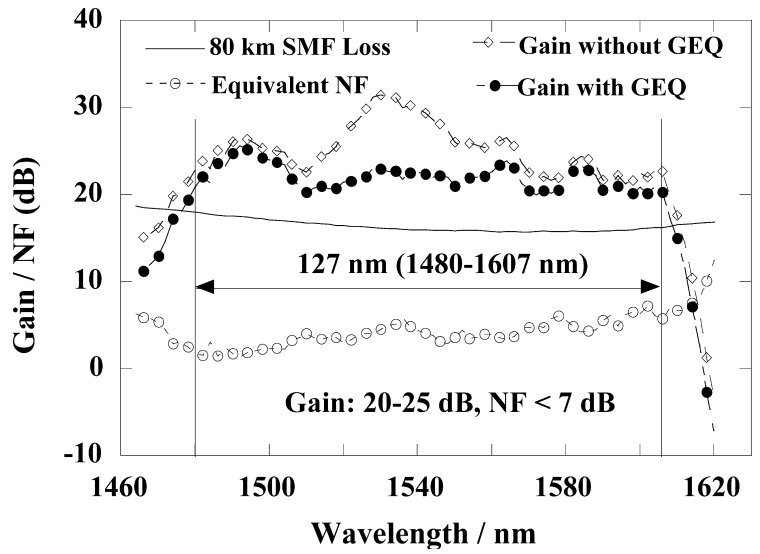

Fig. 16. Total gain spectrum with and without gain equalization, equivalent noise figure and loss spectra for $80-\mathrm{km}$ of SMF.

multi-wavelength pumping. Qin et al. demonstrated a flatter gain profile with and a larger effective bandwidth by increasing the number of pump wavelengths from 2 to 8 using $\mathrm{TeO}_{2}-\mathrm{BaO}-\mathrm{SrO}-$ $\mathrm{Nb}_{2} \mathrm{O}_{5}-\mathrm{P}_{2} \mathrm{O}_{5}-\mathrm{WO}_{3}$ (TBSNPW) and TBZN tellurite fibers. ${ }^{44)}$ The relative gain flatness of an $\mathrm{S}+\mathrm{C}+\mathrm{L}$ band FRA for 8 pump wavelengths is $4.51 \%$ and $11.72 \%$ for TBSNPW and TBZN fibers, respectively. However, the corresponding flatness values for 4 pump wavelengths are both around $20 \%$. This is because an FRA requires a configuration with more than two stages to realize a gain beyond $20 \mathrm{~dB}$ owing to double Rayleigh scattering, ${ }^{45)}$ and a configuration with the polarization multiplexing of two LDs for one pump wavelength owing to the polarization dependence of gain. ${ }^{46)}$ When considering the practical number of pump LDs, we should investigate ways of obtaining a flatter gain profile and a larger effective bandwidth using around 4 pump wavelengths.

5. Stimulated Brillouin scattering (SBS) in telluritebased fiber for amplification and slow light generation $^{14)}$

With stimulated Brillouin scattering, a pump light of fre- 
quency $v$ is scattered by an acoustic wave with frequency $v_{\mathrm{B}}$ of the molecules composing the core glasses, and is consequently emitted with a frequency of $v-v_{\mathrm{B}}$. As with the FRA, the signals can be amplified with a wavelength that is longer than that of the pump light solely by the acoustic vibration frequency $v_{\mathrm{B}}$. However, SBS can amplify the light propagation in a direction opposite to the light.

Figure 17 shows the experimental setup for Brillouin amplification. A CW single frequency laser at $1550 \mathrm{~nm}$ was divided into two parts by a $3 \mathrm{~dB}$ coupler. One part was amplified with an EDFA for use as the pump source, while the other part was frequency downshifted using an optical single-sideband (SSB) modulator by an amount approximately equal to the Brillouin frequency shift for use as the probe signal. For the Brillouin amplification experiments, a $100 \mathrm{~m}$ long tellurite-based fiber with background losses of $59 \mathrm{~dB} / \mathrm{km}$ was used. Figure 18 shows the dependence of the Brillouin gain spectra on the pump power. A peak gain of $29 \mathrm{~dB}$ was achieved with a pump power of 10 $\mathrm{mW}$ at $1550 \mathrm{~nm}$. Figure 19(a) shows the value of the peak Brillouin gain as a function of the pump power. The Brillouin gain coefficients of tellurite-based fiber were calculated by substituting the gain data measured with a pump power of $6 \mathrm{~mW}$ and the parameters of the tellurite-based fiber presented in Table 2 into

$$
G=10 \log \left[\exp \left(g_{\mathrm{B}} L_{\mathrm{eff}} P K / A_{\mathrm{eff}}-\alpha L\right)\right]
$$

which is shown in Fig. 19(b). The peak Brillouin gain coefficient value of $1.6989 \times 10^{-10} \mathrm{~m} / \mathrm{W}$ was obtained for tellurite-based fiber and this is 8.5 times larger than that of silica-based fiber. From Fig. 19(b), a Brillouin shift of $7.97 \mathrm{GHz}$ and a 3-dB Bril-

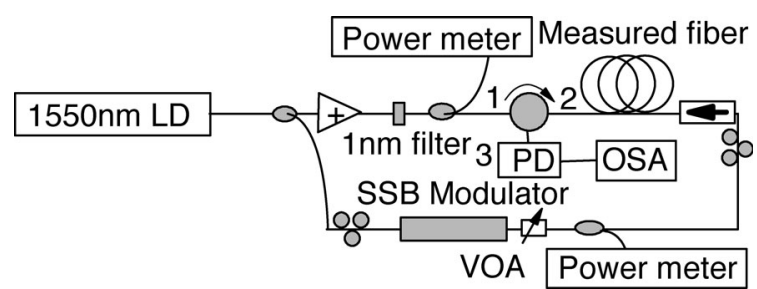

Fig. 17. Experimental setup used for Brillouin amplification.

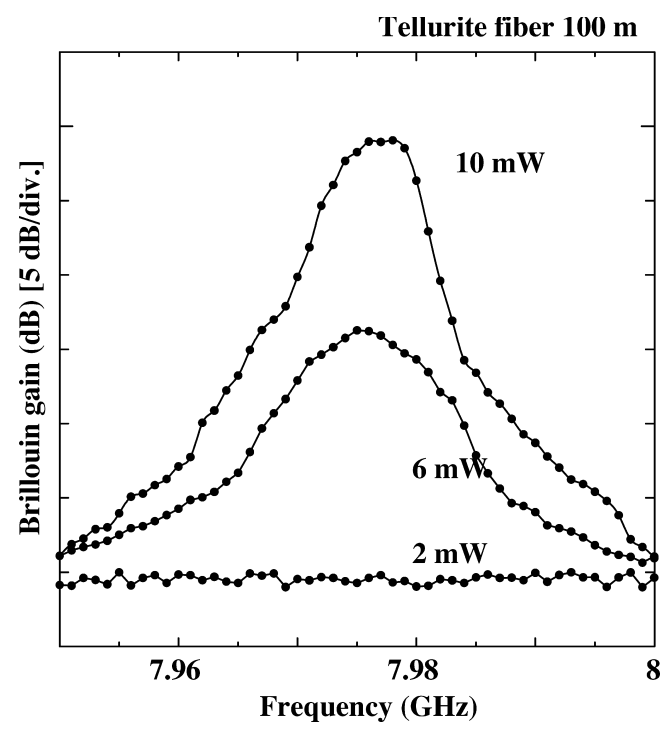

Fig. 18. Brillouin gain spectra vs pump power. louin shift gain linewidth $\left(\Delta v_{\mathrm{B}}\right)$ of $20.98 \mathrm{MHz}$ were obtained for tellurite-based fiber by fitting the Brillouin gain coefficient spectrum with a Lorentzian spectral profile. In addition, the acoustic velocity in this tellurite-based fiber was calculated as $3042.7 \mathrm{~m} / \mathrm{s}$ using the relation $v_{\mathrm{A}}=\Delta v_{\mathrm{B}} \lambda_{\mathrm{p}} / 2 n$ where, $\mathrm{n}$ is the refractive index, $\lambda_{\mathrm{p}}$ the pump wavelength, and $v_{\mathrm{B}}$ the Brillouin shift. The parameters are shown in Table 2.

Recently, Abedin investigated the stimulated Brillouin scattering (SBS) properties and the slow light generation performance in $\mathrm{Er}^{3+}$-doped tellurite fiber with a loss of $\sim 0.5 \mathrm{~dB} / \mathrm{m}$, and confirmed that tellurite fiber performs well as regards slow light generation via SBS. ${ }^{47)}$ The SBS induced time delay per unit power and unit length was also calculated using the measured Brillouin coefficients for the undoped tellurite-based fiber with a low background loss of $20 \mathrm{~dB} / \mathrm{km}$, as defined in ${ }^{48), 49)}$

$$
\Delta t_{\mathrm{d}} /\left(P_{\mathrm{p}} L_{\mathrm{eff}}\right)=\frac{g_{\mathrm{B}} K}{A_{\mathrm{eff}}\left(2 \pi \Delta v_{\mathrm{B}}\right)} .
$$

Measured data for the Brillouin gain coefficients and the tellurite-based fiber parameters shown in Table 2 were used. The calculated results are shown in Fig. 20(a). A peak value of $0.09245 \mathrm{~ns} / \mathrm{mW} / \mathrm{m}$ was obtained for this tellurite-based fiber. Another important parameter with respect to slow light generation is the time delay slope efficiency defined as

$$
S_{\mathrm{dg}}=\Delta t_{\mathrm{d}} / G_{\mathrm{B}} \approx \frac{1}{8.686 \pi \Delta v_{\mathrm{B}}} .
$$

Figure 20(b) shows the time delay as a function of the Brillouin gain, which gives a time slope efficiency of $1.75 \mathrm{~ns} / \mathrm{dB}$.
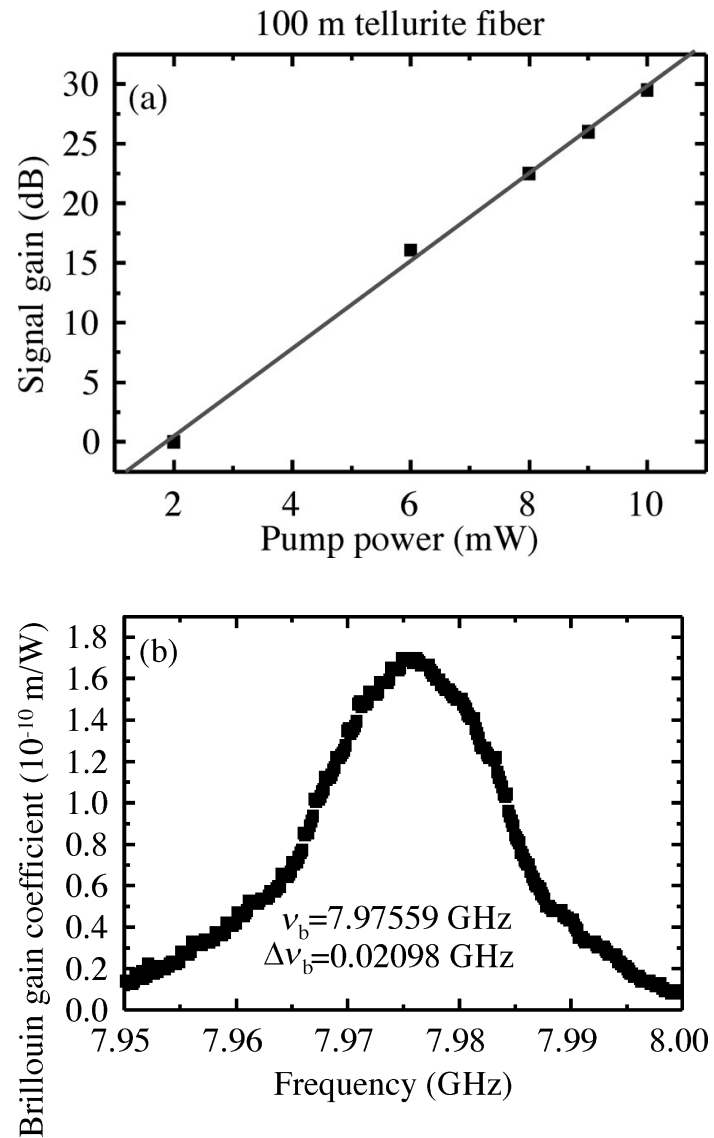

Fig. 19. (a) Value of peak Brillouin gain as a function of pump power, (b) Brillouin gain coefficients of tellurite-based fiber. 
Table 2. Comparison of Nonlinear Optical Properties of sllica, Bismuth Oxide, Tellurite and $\mathrm{As}_{2} \mathrm{Se}_{3}$ Chalcogenide Fibers

\begin{tabular}{lcccc}
\hline \multicolumn{1}{c}{ Parameters } & Silica & Bismuth oxide ${ }^{15}$ & Tellurite & Chalcogenide $^{48}$ \\
\hline Refractive index $(\mathrm{n})$ & 1.45 & 2.22 & 2.03 & 2.8 \\
Brillouin gain coefficient $\left(g_{\mathrm{B}}, \mathrm{m} / \mathrm{W}\right)$ & $2 \times 10^{-11}$ & $6.43 \times 10^{-11}$ & $1.6989 \times 10^{-10}$ & $6.08 \times 10^{-9}$ \\
Brillouin frequency shift $\left(\nu_{\mathrm{B}}, \mathrm{GHz}\right)$ & 10.86 & 8.825 & 7.97 & 7.968 \\
Brillouin gain bandwidth $\left(\Delta \nu_{\mathrm{B}}, \mathrm{MHz}\right)$ & 25 & 32 & 20.98 & 45 \\
Background loss $(\mathrm{dB} / \mathrm{m})$ & 0.0005 & 0.8 & 0.0588 & 1 \\
$A_{\text {eff }}\left(\mu \mathrm{m}^{2}\right)$ & 50 & 3.08 & 6.9697 & 39 \\
$\frac{g_{\mathrm{B}} K}{A_{\text {eff }}\left(2 \pi \Delta v_{\mathrm{B}}\right)}, \mathrm{ns} / \mathrm{mW} / \mathrm{m}$ & 0.00127 & 0.067 & 0.09257 & 0.2 \\
Time delay slope efficiency & & & & \\
$\left(\mathrm{S}_{\mathrm{dg}}=\frac{1}{8.686 \pi \Delta \nu_{\mathrm{B}}}, \mathrm{ns} / \mathrm{dB}\right)$ & 1.46 & 1.1452 & & 0.82 \\
\hline
\end{tabular}
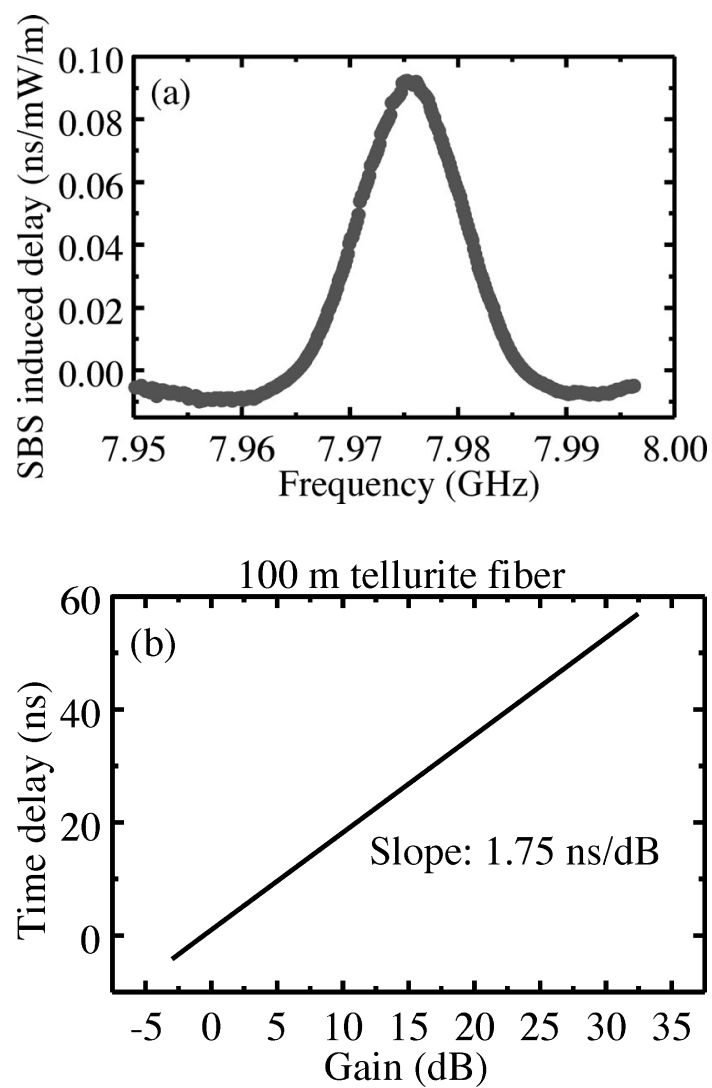

Fig. 20. (a) SBS induced time delay per unit power and per unit length, (b) time delay as a function of Brillouin gain.

This value calculated using tellurite-based fiber is higher than the time delay slope efficiencies previously obtained for silica, bismuth oxide-based and $\mathrm{As}_{2} \mathrm{Se}_{3}$ chalcogenide fibers. Equation (3) shows that a smaller $\Delta v_{\mathrm{B}}$ leads to a larger $S_{\mathrm{dg}}$. As shown in Table 2, tellurite fiber exhibits the smallest $\Delta v_{\mathrm{B}}$, so it exhibits the largest $S_{\mathrm{dg}}$ of these four types of fibers.

Furthermore, taking the background loss into consideration, the dependence of the SBS induced time delay per unit power on the fiber length was calculated by employing the following equation
Background loss (DSF $\sim 5 \mathrm{~dB} / \mathrm{km}$; Bismuth $\sim 800 \mathrm{~dB} / \mathrm{km}$, Tellurite $\left.20 \mathrm{~dB} / \mathrm{km}, \mathrm{As}_{2} \mathrm{Se}_{3} \sim 1000 \mathrm{~dB} / \mathrm{km}\right)$

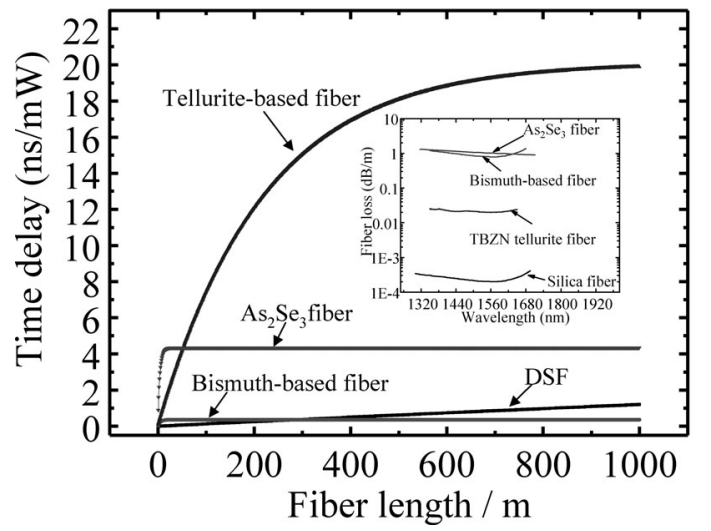

Fig. 21. Dependence of SBS induced time delay per unit power on fiber length for four types of fibers. Inset: background losses of these fibers.

$$
\frac{\Delta t_{\mathrm{d}}}{P_{\mathrm{p}}}=\frac{g_{\mathrm{B}} K}{A_{\mathrm{eff}}\left(2 \pi \Delta \nu_{\mathrm{B}}\right)} \times(1-\exp (-\alpha L)) / \alpha .
$$

Here, background losses for silica, bismuth-based, telluritebased and $\mathrm{As}_{2} \mathrm{~S}_{3}$ fibers of $0.5,800,20$ and $1000 \mathrm{~dB} / \mathrm{km}$, respectively, were selected. Figure 21 shows the calculated results. The inset in Fig. 21 shows the background losses of these four types of fibers. Tellurite-based fiber exhibits the largest time delay per unit power of $19.9 \mathrm{~ns} / \mathrm{mW}$ as a result of its low background loss and relatively higher Brillouin gain coefficient.

\section{Carrier-envelope offset locking with low pulse energy $^{23)}$}

A carrier-envelope offset (CEO)-locked frequency comb at telecommunication wavelengths with a downsized and highrepetition-rate laser system could provide an optical frequency "ruler" in a robust, power-efficient fiber-optics package that would be suitable for a variety of applications. CEO frequency detection with an f-to-2f self-referencing interferometer requires an optical bandwidth of more than an octave (a factor of 2 in frequency). To reduce the pulse energy needed for the generation of an octave-bandwidth spectrum for the downsized laser system, a method was proposed for locking the CEO by employing the 


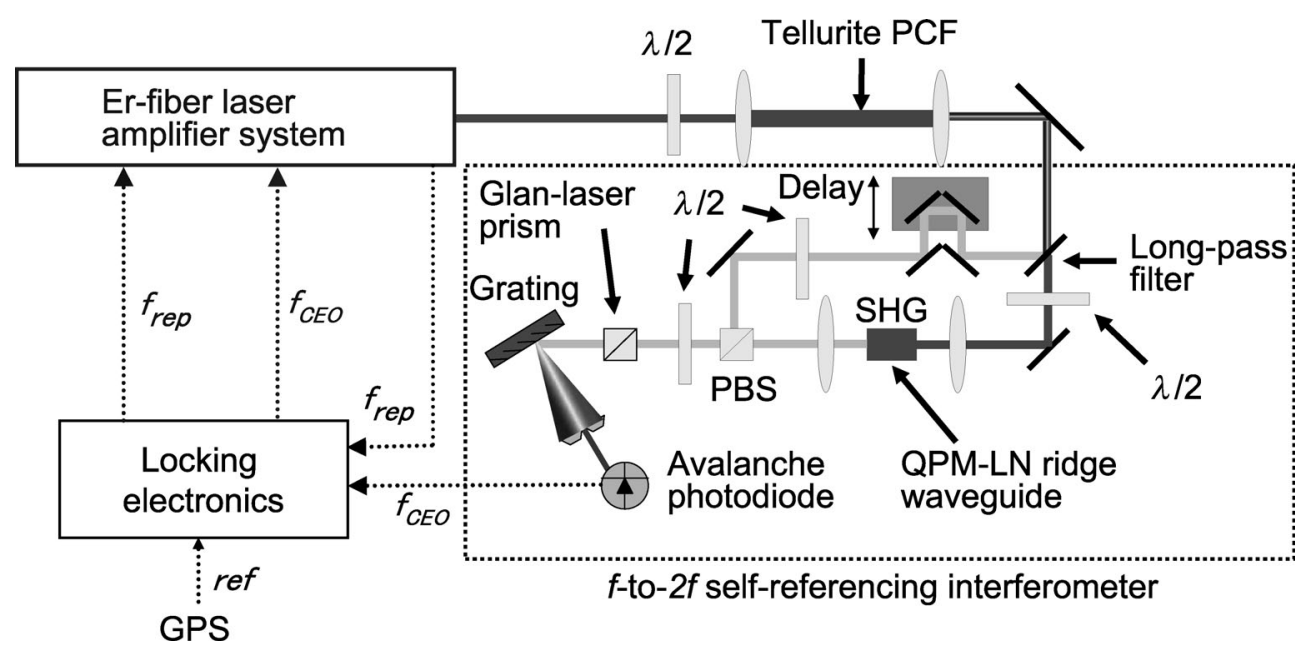

Fig. 22. Experimental setup for the CEO locking with low pulse energy: $f_{\mathrm{CEO}}$, CEO frequency; $f_{\text {rep }}$, repetition rate; PBS, polarization beam splitter.

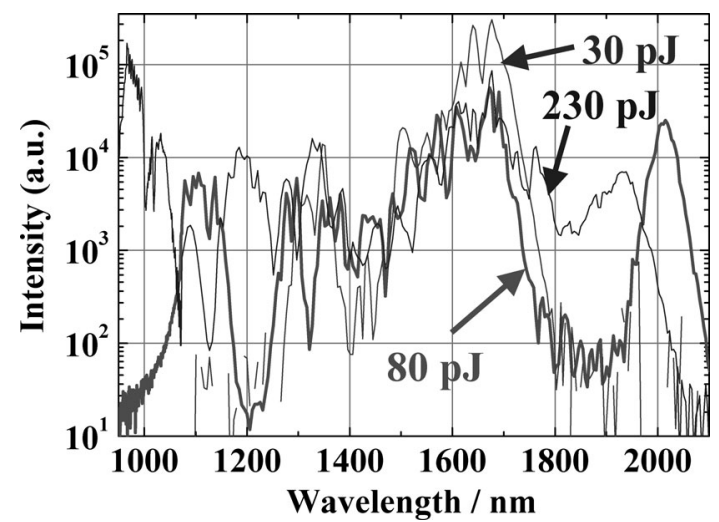

Fig. 23. Spectrum generated in a $30-\mathrm{cm}-$ long tellurite-PCF by using fiber coupling pulse energies 30,80 , and $-230 \mathrm{pJ}$. Each SC spectrum in the graph has the same intensity at $1560 \mathrm{~nm}$.

tellurite PCF described in section 3.

Figure 22 shows the experimental setup. A passively modelocked Er-fiber laser amplifier system is used. The amplifier laser drives a 100-fs, 1-nJ laser pulse with a center wavelength of 1560 $\mathrm{nm}$. The repetition frequency of the fiber laser system is controlled to $250 \mathrm{MHz}$. The output power from the amplifier laser is collimated in free space and then launched into the tellurite PCF with a typical efficiency of $29 \%$ by using an objective lens $(\mathrm{NA}=0.8)$. The optical output spectrum after the tellurite PCF spans more than an octave. The CEO frequency $f_{\text {CEO }}$ is measured with an f-to- $2 \mathrm{f}$ self-referencing interferometer. A long-pass filter transmits infrared components at $1930 \mathrm{~nm}$. These components are then frequency-doubled into the QPM-LN waveguide ${ }^{50)}$ and recombined with a $965-\mathrm{nm}$ beam propagating through an arm of the f-to- $2 \mathrm{f}$ self-referencing interferometer. From a signal selected with a grating, the heterodyne beat between the interference components yields a frequency difference $f_{\text {CEO }}$. The CEO signal is phase-locked to $f_{\text {CEO }}=20 \mathrm{MHz}$ using a feedback circuit.

Figure 23 shows the dependence of the SC spectrum of the tellurite PCF on the fiber coupling pulse energy. It was found that an SC spanning more than an octave (950-2100 nm) at the -30$\mathrm{dB}$ level can be generated with a fiber-coupling pulse energy of $80 \mathrm{pJ}$ and a $30-\mathrm{cm}$ long tellurite PCF. However, it was not pos-
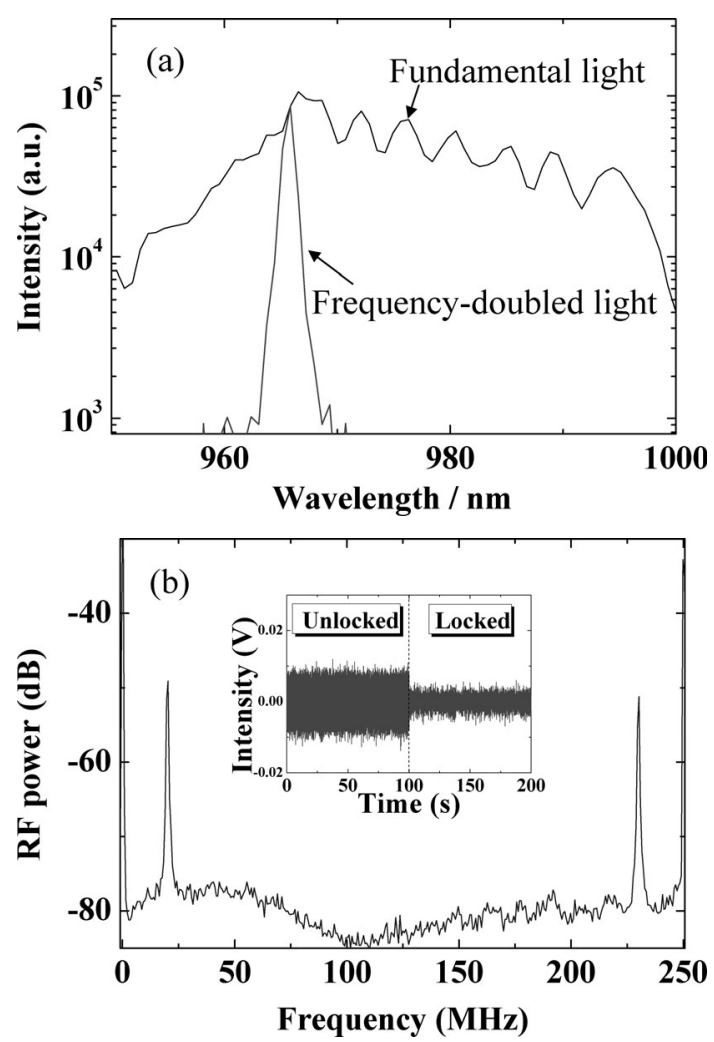

Fig. 24. (a) Spectrum between the fundamental light in the $965-\mathrm{nm}$ region and the frequency-doubled 1930-nm light when a 230-pJ pulse was launched into the tellurite PCF. (b) Self-reference beat signal of the 250-MHz laser. Resolution bandwidth is $100 \mathrm{kHz}$. Inset: Phase difference between beat signal and local oscillator.

sible to observe the beat signal with the 80-pJ fiber-coupling pulse energy, probably because of the low output power from the tellurite PCF. Therefore, the fiber coupling pulse energy was increased and a 230-pJ pulse energy launched into the PCF. Figure 24(a) shows the spectrum between the fundamental light and the second harmonic generated by propagation in the QPM-LN ridge waveguide. The largest beat signal was obtained in the 965- 


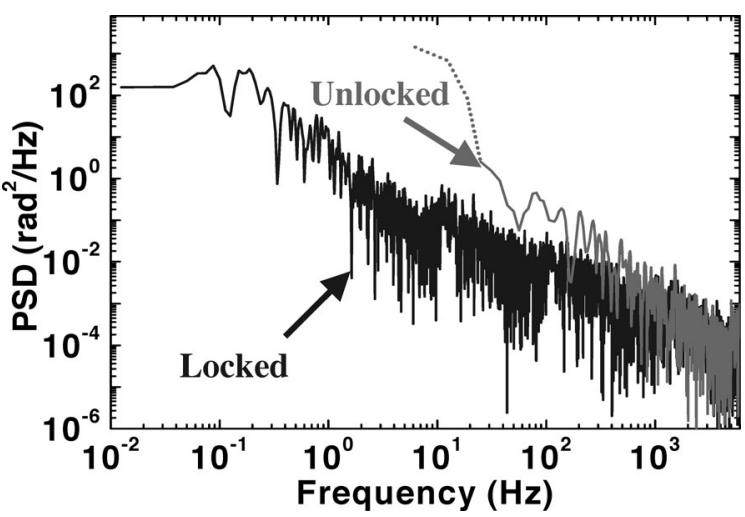

Fig. 25. Power spectrum density of the CEO beat signal.

$\mathrm{nm}$ region. Figure 24(b) shows that the beat signal between the frequency-doubled light at $1930 \mathrm{~nm}$ and the fundamental light at $965 \mathrm{~nm}$ was detected. The beat signal had a signal-to-noise ratio of about $30 \mathrm{~dB}$. The beat signal was locked at a $20-\mathrm{MHz}$ reference frequency by controlling the $980-\mathrm{nm}$ pump laser power using a feedback circuit. The inset in Fig. 24(b) shows that the difference signal between the beat signal and the local oscillator becomes smaller with the CEO lock. Figure 25 shows the power spectrum density (PSD) of the phase noise with and without the CEO lock. Without the CEO lock, it was difficult to measure the PSD signal at less than $1 \mathrm{~Hz}$ because of carrier frequency fluctuation. This means that a feedback loop with the CEO lock suppresses phase noise at frequencies less than $1 \mathrm{~Hz}$. We confirmed that the $\mathrm{CEO}$ could be locked in the system.

\section{Conclusion}

In summary, this paper reviewed research on tellurite-based glasses, and considered the process for fabricating fiber with a low background loss and fiber applications to optical communication networks. By purifying the raw materials and using a novel PCF fabrication process, we achieved low background losses for $\mathrm{Er}^{3+}$-doped, and undoped step-index tellurite-based fibers and a tellurite-based PCF.

As regards optical communications applications, EDTFAs, fiber Raman and Brillouin amplification, slow light generation and a CEO-locked frequency comb were studied. A seamless, low noise and gain flattened $\mathrm{C}+\mathrm{L}$ band EDTFA was realized and an $\mathrm{S}+\mathrm{C}+\mathrm{L}$ band amplifier with gain bandwidths was constructed by combining the EDTFA and TDFFA in parallel. Furthermore, to overcome certain problems a distributed/discrete hybrid tellurite- and silica-based FRA was constructed as an $\mathrm{S}+\mathrm{C}+\mathrm{L}$ band WDM repeater, and it provided a $127-\mathrm{nm}$ bandwidth and an equivalent noise figure below $7 \mathrm{~dB}$ of $1480-1607$ $\mathrm{nm}$. These amplifiers could be employed in WDM systems with the $\mathrm{C}+\mathrm{L}$ or $\mathrm{S}+\mathrm{C}+\mathrm{L}$ band covering the low attenuation of installed fibers. Next, the Brillouin gain coefficients were investigated and the potential performance of a tellurite-based fiber for slow light generation was clarified on the basis of the Brillouin gain characteristic. Tellurite-based fiber exhibits the largest time delay per unit power and is thus a promising candidate for use in the development of memories and optical delay lines that would be compatible with fiber-optic communication. Finally, a CEO-locked frequency comb with a lower fiber coupling pulse energy was demonstrated by using a tellurite-based PCF. The reported method has the potential to lock the CEO with a lower pulse energy and thus provide a low-noise and high-accuracy optical frequency comb at telecommunication wavelengths. The results confirm that tellurite-based fibers with low background loss can provide attractive functional applications in the optical communication field.

Acknowledgements The author thanks Professor Y. Ohishi, Dr. H. Masuda, Dr. A. Ishizawa, and many colleagues at NTT Photonics Laboratories.

\section{References}

1) B. C. Hwang, S. Jiang, T. Luo, K. Seneschal, G. Sorbello, M. Morrell, F. Smektala, S. Honkanen, J. Lucas and N. Peyghambarian, IEEE Photon. Technol. Lett., 13, 197-199 (2001).

2) S. Aozasa, A. Mori, K. Oikawa, M. Yamada, H. Ono, H. Kanbara and K. Naganuma, OFC/NFOEC'08, OTuN4 (2008).

3) Y. Ohishi, T. Kanamori, T. Kitagawa, S. Takahashi, E. Snitzer and G. H. Sigel Jr., Opt. Lett., 16, 1747-1749 (1991).

4) S. Aozasa, H. Masuda and M. Shimizu, J. Lightwave Technol., 24, 3842-3848 (2006).

5) N. Sugimoto, J. Am. Ceram. Soc., 85, 1083-1088 (2002).

6) A. Mori, Y. Ohishi and S. Sudo, Electron. Lett., 33, 863-864 (1997).

7) H. Tawarayama, E. Ishikawa, K. Yamanaka, K. Ito, K. Okada, H. Aoki, H. Yanagita, Y. Matsuoka and H. Toratani, J. Am. Ceram. Soc., 83, 792-796 (2000).

8) N. Sugimoto, T. Nagashima, T. Hasegawa, S. Ohara, K. Taira and K. Kikuchi, OFC2004, PDP26 (2004).

9) A. Mori, H. Masuda, K. Shikano and M. Shimizu, J. Lightwave Technol., 21, 1300-1306 (2003).

10) M. Asobe, Opt. Fib. Technol., 3, 142-148 (1997).

11) A. Mori, Y. Ohishi, M. Yamada, H. Ono, Y. Nishida, K. Oikawa and S. Sudo, OFC'97, PD1 (1997).

12) Y. Ohishi, A. Mori, M. Yamada, H. Ono, Y. Nishida and K. Oikawa, Opt. Lett., 23, 274-276 (1998).

13) A. Mori, K. Kobayashi, M. Yamada, T. Kanamori, M. Yamada, K. Oikawa, Y. Nishida and Y. Ohishi, Electron. Lett., 34, 887-888 (1998).

14) G. Qin, H. Sotobayashi, M. Tsuchiya, A. Mori, T. Suzuki and Y. Ohishi, J. Lightwave Technol., 26, 492-498 (2008).

15) J. H. Lee, T. Tanemura, K. Kikuchi, T. Nagashima, T. Hasegawa, S. Ohara and N. Sugimoto, Opt. Lett., 30, 16981700 (2005).

16) K. S. Abedin, Opt. Lett., 31, 1615-1617 (2006).

17) G. P. Agrawal, "Nonlinear Fiber Optics," Academic Press, New York (1995) pp. 370-385.

18) R. H. Stolen, "Polarization Effects in Fiber Raman and Brillouin lasers," IEEE J. Quantum Electron., 15, 1157-1160 (1979).

19) K. Inoue, J. Lightwave Technol., 10, 1553-1561 (1992).

20) A. Mori, H. Masuda and M. Shimizu, OFC2003, ThB2 (Invited) (2003).

21) J. K. Ranka, R. S. Windeler and A. J. Stentz, Opt. Lett., 25, 796-798 (2000).

22) A. Mori, K. Shikano, K. Enbutsu, K. Oikawa, K. Naganuma, M. Kato and S. Aozasa, ECOC2004, Th3.3.6 (2004).

23) A. Ishizawa, T. Nishikawa, S. Aozasa, A. Mori, O. Tadanaga, M. Asobe and H. Nakano, Opt. Express., 16, 4706-4712 (2008).

24) D. J. Jones, S. A. Diddams, J. K. Ranka, A. Stentz, R. S. Windeler, J. L. Hall and S. T. Cundiff, Science, 288, 635-639 (2000).

25) S. A. Diddams, D. J. Jones, J. Ye, S. T. Cundiff, J. L. Hall, J. K. Ranka, R. S. Windeler, R. Holzwarth, T. Udem and T. W. Hänsch, Phys. Rev. Lett., 84, 5102-5105 (2000).

26) S. T. Cundiff, J. Phys. D: Appl. Phys., 35, R43-R59 (2002).

27) J. S. Wang, E. M. Vogel and E. Snitzer, Opt. Mater., 3, 187203 (1994).

28) Y. Ohishi, S. Sakaguchi and S. Takahashi, Electron. Lett., 22, 1034-1035 (1986). 
29) D. C. Tran, C. F. Fisher and G. H. Siegel, Electron. Lett., 18, 657-658 (1982).

30) K. Tajima and J. Zhou, IEICE Trans. Electron., E88-C, 870875 (2005)

31) H. Ebendorff-Heidepriem, P. Petropoulos, R. Moore, K. Frampton, D. J. Richardson and T. M. Monro, J. Non-Cryst. Solid, 345\&346, 293-296 (2004).

32) T. Nagashima, T. Hasegawa, S. Ohara and N. Sugimoto, ECOC2006, We1.3.2 (2006).

33) F. Smektala, F. Desevedavy, L. Brilland, P. Houizot, J. Troles and N. Traynor, Proc. of SPIE, 6588, 658803 (2007).

34) K. Naganuma, K. Mogi and H. Yamada, Opt. Lett., 15, 393395 (1990).

35) H. Ono, A. Mori, K. Shikano and M. Shimizu, IEEE. Photon. Technol. Lett., 14, 1073-1075 (2002).

36) A. Mori, T. Sakamoto, K. Kobayashi, K. Shikano, K. Hoshino, T. Kanamori, Y. Ohishi and M. Shimizu, J. Lightwave. Technol., 20, 822-827 (2002).

37) A. Mori, T. Sakamoto, K. Shikano, K. Kobayashi, K. Hoshino and M. Shimizu, Electron. Lett., 36, 621-622 (2000).

38) T. Sakamoto, A. Mori and M. Shimizu, OFC2004, ThJ5 (2004).

39) F. L. Galeener, J. C. Mikkelsen Jr., R. H. Geils and W. J. Mosby, Appl. Phys. Lett., 32, 34-36 (1978).
40) T. Sekiya, N. Mochida, A. Ohtsuka and M. Tonokawa, J. NonCryst. Solids, 144, 128-144 (1992).

41) G. S. Murugan, T. Suzuki and Ohishi, Appl. Phys. Lett., 86, 161109-161111 (2005).

42) H. Masuda, A. Mori, K. Shikano and M. Shimizu, J. Lightwave. Technol., 24, 504-515 (2006).

43) H. Takara, H. Masuda, K. Mori, K. Sato, K. Inoue, T. Ohara, A. Mori, M. Kohtoku, Y. Miyamoto, T. Morioka and S. Kawanishi, Electron. Lett., 39, 382-383 (2003).

44) G. Qin, R. Jose and Y. Ohishi, IEEE. Photon. Technol. Lett., 25, 2727-2738 (2007).

45) H. B. Hansen, L. Eskildsen, A. J. Stents, T. A. Strasser, J. Judkins, J. J. DeMarco, R. Pedrazzani and D. J. DiGiovanni, IEEE. Photon. Technol. Lett., 10, 159-161 (1998).

46) J. Zhang, V. Dominic, M. Missey, S. Sanders and D. Mehuys, OAA2000, OMB4 (2000).

47) K. S. Abedin, G.-W. Lu and T. Miyazaki, CLEO2007, CThH6 (2007).

48) K. Y. Song, M. G. Herraez and L. Thevenaz, Opt. Express, 13, 82-88 (2005).

49) K. Y. Song, K. S. Abedin, K. Hotate, M. G. Herraez and L. Thevenaz, Opt. Express, 14, 5860-5865 (2006).

50) Y. Nishida, H. Miyazawa, M. Asobe, O. Tadanaga and H. Suzuki, Electron. Lett., 39, 609-611 (2003).

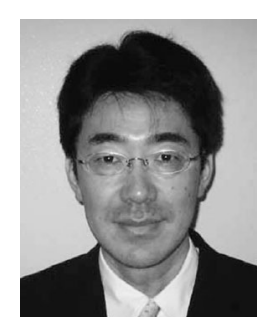

Atsushi Mori Atsushi Mori received B.S. and M.S. degrees in physics from Tohoku University, Sendai, Miyagi in 1989 and 1991, respectively, and was awarded a Ph.D. in electronic engineering by Tokyo University, Tokyo in 2005. He joined NTT Optoelectronics Laboratories (now Photonics Laboratories) in 1991, where he engaged in research on multicomponent glass fiber including oxide, fluoride and chalcogenide glass fiber for optical fiber amplifiers. Since 1995, he has mainly been engaged in research on wideband optical fiber amplifiers using $\mathrm{Er}^{3+}$-doped tellurite fibers and on tellurite fiber as a fiber Raman amplifier medium. He received the 1996 JSAP lecture award and the 2000 IEICE achievement award. He is a member of the Institute of Electronics, Information and Communication Engineers (IEICE) of Japan, and the Japan Society of Applied Physics. 